\title{
FUNCTION, SEMANTICS AND PRAGMATICS OF EVALUATIVE ADJECTIVES IN FICTIONAL DISCOURSE
}

\author{
Iryna Nikitochkina \\ Department of Foreign Languages for Humanities \\ Yurii Fedkovych Chernivtsi National University, \\ 2 Kotsiubynskoho str., Chernivtsi, Ukraine, 59343 \\ IrynaVB@bigmir.net
}

\begin{abstract}
We constantly assess other people, objects, phenomena, and events around us. The process of evaluation is based on a set of values pertaining to an individual and on certain norms and traditions of the society. The use of certain language means expressing people's attitudes may shed light on such complex cognitive process. Evaluative adjectives are frequently used and form an integral part of the world view in conceptual and language aspects.

The present paper provides the results of syntactic, semantic, functional and pragmatic peculiarities of evaluative adjectives in fiction.
\end{abstract}

Keywords: adjectival phrase, boosters, evaluation, evaluative adjectives, fictional discourse, functional semantics, hedges, value.

\section{Introduction}

The main function of human language is communication by means of coding and decoding information. The information is processed and transformed into certain mental representation in human consciousness and that process is constantly accompanied by language development.

Being reflected on language level, values are verbalized with the help of special evaluative words. The latter are directly connected to the speaker and show his/her attitude towards reality. When it comes to evaluation and axiology, such part of speech as adjectives traditionally comes to the foreground. Adjectives most often express evaluation in language.

\section{Analysis of literary data and statement of the problem}

While nouns and verbs have been studied broadly and extensively, the adjective class has received less attention. In recent years the number of works published on adjectives has increased, as debate as to the universal nature of the adjective class has become more widespread. Studies in this area concern syntax and semantics of adjectives [1], functioning of adjectives in discourse [2], relations with other lexical categories [3], typology of various adjective classes [4, 5], and attributive adjectives [6].

In English grammar adjectives, as a separate word class, are distinguished according to such criteria:

- they can function in attributive position;

- they can function in predicative position;

- they can be premodified by the intensifier very;

- they can accept comparison, i. e. the comparative and superlative forms, whether inflected or periphrastic;

- they can function as direct object [7].

Most of foreign linguists agree with the aforementioned characteristics of adjectives as a part of speech, however, certain additional features have also been suggested:

- the ability to form adverbs by means of flexionly: e. g. cheap - cheaply, expensive - expensively, worthy - worthily [8]; fishing [9];

- the possibility to be used as a modifier following a noun: e. g. I've got a friend keen on

- possible use in combination with the verbs denoting physical action, thus, forming structures resembling phrasal verbs: e. g. The thieves broke open the safe [10]. 
Despite the variety of approaches to determining the category of adjectives all researchers indicate the expression of quality or feature in combination with nouns. So, in our opinion, the most generalized definition of an adjective is the following: adjective is a part of speech characterized by categorial meaning of feature, grammar category of degrees of comparison and syntactic function of an attribute or a predicative.

Evaluative adjectives, in their turn, have been viewed as a coherent syntactic and semantic class for more than forty years $[11,12]$. This group of adjectives has gained recent attention, however, from the standpoint of syntax aiming at extending analyses of argument alignment in the verbal domain to the adjectival domain $[13,14]$. In semantic studies evaluative adjectives are examined to interpret 'vague' predicates [15]. However, evaluative adjectives still require complex investigation including lexicological, syntactic, semantic and pragmatic aspects of their use. Hence, the topicality of our research is stipulated by the necessity to perform a systematic study of evaluative adjectival phrases in various types of discourse.

\section{Aim and tasks of research}

The objective of the given paper is to determine system and idiolect features of evaluative adjectival phrases in fictional discourse. The subject of our research underlies in structural, syntactic, lexical and functional characteristics of evaluative adjectival phrases. The object encompasses system and idiolect characteristics of evaluative adjectives and adjectival phrases in fiction.

For the achievement of the set aim it is necessary to accomplish such tasks:

- to determine the functions performed by evaluative adjectives in syntax and represent their basic phrase models;

- to analyze the distribution of evaluative adjectives, study their relations with denoted nouns, and model their functional semantic microfield;

- to establish the influence of hedging and boosting devices on evaluative meaning in fictional discourse.

\section{Materials and methods}

The problem of different level syntactic units is of current importance, because it can contribute to better understanding of utterance and text structure peculiarities. In spite of considerable amount of fundamental studies the issue of defining a phrase in modern linguistics is still controversial and debated.

G. D. Morley states that whilst there is frequently an identity between the class of phrase and the class of word group, there is, of course, no automatic correspondence between them. Consequently, a given class of phrase might be able to be realized by different classes of word group. Thus, whereas the revised formula in The revised formula looks interesting is straightforwardly a nominal phrase realized by a noun group, the noun group last week in I saw her last week operates as an adverbial phrase. The preposition group in the garden in Ruth is in the garden functions as an adverbial phrase, but the preposition group in good health in Ruth seems in good health serves as an adjectival phrase, and the preposition group to Mary in Ruth gave the map to Mary is a nominal phrase [16].

A phrase is regarded as a unit which functions syntactically like a particular word class. This is irrespective of the degree of structural complexity of the phrase or of the class of word realizing its head. To reinforce the contrast the difference then between the formal criteria which determine the class of word group and the functional criteria which determine classes of phrase, phrase classes are labeled with their relevant derivative adjectival label. Thus, we refer to a nominal phrase (not a noun phrase) as one which has a (syntactically) nominal function, in other words which functions syntactically like a noun or determiner-pronoun. Similarly, an adjectival phrase (not adjective phrase) has a (syntactically) adjectival function [16].

Adjectival phrases have an adjectival function in representing in the syntax a feature or quality which is attributed to a (typically) preceding nominal phrase, e. g. The concert was very interesting. They thus answer questions of the type "What is Xlike?". As with other phrases, they may be realized by single words or larger word groups, e. g. It was small/ quite funny/ extremely 
odd / pleasant enough/very quick indeed/cleaner than your room/far bigger than I imagined [16]. B. O'Dwyer also adds that the head adjective of the phrase is generally the last word, which may only be one in a series of qualifying words. Although these qualifying words usually precede the head adjective, they may also occur after it [17].

Adjectival phrases are not infrequently also realized by preposition groups, e. g. Jill is in good shape. That watch must be of considerable value. The adjectival phrases in these examples are all predicative, all separated from the subject which they describe. However, an adjectival grouping acting as attributive modifier with a nominal phrase, e. g. a very thorny problem, would be treated not as an adjectival phrase but as an adjective group [16].

There may be very little difference between a nominal phrase and an adjectival phrase in structures where adjectives occur before the word they qualify. Most nominal phrases consist of a head noun plus one or more adjectives, or indeed an adjectival phrase itself [17].

According to P. Strazny, adjectival phrases modifying nominal heads fall into the descriptive and classifying subtypes: descriptive adjectival phrases focus on a certain property of the noun that functions as a nominal head, as in the high wall; classifying adjectival phrases assign a label of type or class to the noun in function of nominal head, as in the regimental headquarters [18].

More complex adjective phrases are most commonly found as the complements of verbs such as be or seem, or following the head in a noun phrase. They generally cannot be used as modifiers preceding the heads of noun phrases (for example, consider *the angry at the committee man vs. the angry man vs. the man angry at the committee). Adjective phrases may also take a degree modifier preceding the head, as in the adjective phrase very angry or somewhat fond of Mary. More complex degree modifications are possible, as in far too heavy and much more desperate. Finally, certain constructs have degree modifiers that involve their own complement forms, as in too stupid to come in out of the rain, so boring that everyone fell asleep, and as slow as a dead horse [19].

In our research we have analyzed the usage of 5 evaluative adjectives possessing a common root valu(e). They are: invaluable, valuable, valued, valueless and unvaluable. The material for study consists of 317 text fragments that have been selected from fictional discourse of British National Corpus $(15,644,926$ words) [20].

\section{Experimental procedures and results}

\section{1. Syntax}

First of all we have focused attention on the syntactic functions of the researched adjectives in sampled sentences. The results may be generalized in the following way: in $59 \%$ of occurrences the evaluative adjectives are used attributively, while in $41 \%$ of examples they are used predicatively. The adjective valued only performs the function of an attribute in all the registered illustrations.

(1) The powder he would throw away but the information the poisoner had provided was invaluable (BNC:H9C).

(2) The Wolverines' borrowed silks lent them invaluable seconds wherein to close with those guards and sever their throats...( BNC:CJJ).

(3) In spare moments she gave Rachaela boxes of jewellery or coins to sort, unvaluable items often to be highly priced (BNC:GUM).

(4) She is valuable to them but her value has its limits (BNC:CJX).

(5) On the other hand, he could find he had been selected to unload a valuable cargo such as palm kernels (BNC:B3J).

(6) My comments on his work were valuable only as an irritating pretext which permitted him to lecture me on Art (BNC:G1A).

(7) Lovely fire was glowing in the grate, and the dark oil-paintings - cherished but valueless heirlooms from their father's family - were gaily decorated (BNC:BMU).

(8) The money seems valueless to him (BNC:J13).

(9) Silk, jade and spices became valued commodities (BNC:CM1).

(10) Shannon studied him closely, curious to see the' old and valued friend' for herself (BNC:HA9). 
In fictional discourse three basic syntactic models with evaluative adjectives have been determined: (1) Adj+N, (2) V+Adj, and (3) Adv.+Adj. These basic syntactic models may have a few different variants, such as N+Adj (12), Adv+Adj+N (14), Pn+Adj+N (13), V+Pn+Adj (15), Adj+ $+\operatorname{Adj}+\mathrm{N}(16), A d v+A d v+\operatorname{Adj}(11), A d j+A d v(17)$. All these models form the realization of attributive and predicative functions of the adjectives.

(11) My shop is considerably more valuable than your barrow and it also derives a far larger income (BNC:K8T).

(12) He had a clear, sceptical and analytical mind, valuable to his boss (BNC:H85).

(13) Now, Miss Gilberd, our valued teacher of the lower forms, will be in classroom $2 \mathrm{~B}$ to talk to anybody (BNC:H8Y).

(14) Now he must either spend countless valuable minutes retrieving the escaped marbles, or he could ignore them ... (BNC:ACV).

(15) ... the little gadget peeled apples, chipped potatoes, sliced onions and generally made itself invaluable to the busy housewife (BNC:FPM).

(16) ... so you will have first-hand invaluable knowledge of what it looks like and how efficient it is (BNC:HA5).

(17) He knew his position was dangerous, but considered his life was not valuable enough to worry about (BNC:FRE).

\section{2 Functional Semantics}

The next aspect to consider is functional semantics. The nouns that are qualified by the adjectives under research belong to such semantic domains: Time (18), Person (19), Social Position (20), Real Estate (21), Money (22), Possession (23), Object (24), Art (25), Animal (26), Jewellery (27), Substance (28), Technology (29), Furniture (30), Life (31), Cargo (32), Paper (33), Attire (34), Help (35), Mind (36), Information (37), Experience (38), and Arms (39).

(18) Because of him she had had to waste valuable days sightseeing, all the time aware of him breathing down her neck (BNC:JY8).

(19) ... she'll squander herself on a man as truly valueless as Florian Jones, and ignore both his marriage and his other affairs (BNC:H9L).

(20) It was when the friend of the family, Donald Templeton, the trusted and valued doctor who attended both Farr and his wife, came to call ... (BNC:ASS).

(21) Purely from a financial perspective, have you any idea how much more valuable the cottage will be when it's known to be one of Piers's creations ... (BNC:H8H).

(22) The word was passed around, rapidly, almost secretly, like a small valuable coin (BNC:K8V).

(23) The object is a prized possession of the God-Kings, very valuable. Perhaps his most valuable acquisition, worth than planet's ransom (BNC:G3G).

(24) ... the scramble for work was becoming more and more intense as family debts grew and many valued and treasured items found their way into the local pawnshops (BNC:EA5).

(25) The few pictures - mainly landscape watercolours in gilt frames - were conservative, unobtrusive and probably valuable (BNC:CKB).

(26) 'Then,' said Mrs Cornett,' although Tobermory is a valuable cat, he and the gardener's cat must die (BNC:FSK).

(27) Apparently she agreed to marry him and he gave her a very valuable ring (BNC:JY2).

(28) From certain of its volcanos poured rivers of lava rich in transuranic elements including psycurium, invaluable in the crafting of psychic hoods and force swords such as Marine Librarians could use (BNC:CJJ).

(29) In fact, he'd beaten the crap out of two bailiffs and then been caught in possession of several extremely valuable and extremely stolen computers (BNC:HJC).

(30) The wall opposite the sink and the window was covered with an oak dresser, very old and probably valuable, if it had been possible to remove it from the wall without its collapse (BNC:C8T).

(31) I was facing a good chance of losing my valuable reputation as an interplanetary courier. And maybe my even more valuable life (BNC:G3G). 
(32) What could a lorry be carrying that its load was so valuable to a thief as to make Hatton's a feasible reward? (BNC:A73).

(33) ... you may recall that Downton lost two very valuable contracts with players in tennis and golf (BNC:CS4).

(34) How she would have managed had not Mrs Carson handed down two dresses, both of fine cotton, Ruth didn't know. They were invaluable (BNC:CB5).

(35) I am sure Mr Waring requires your invaluable assistance! (BNC:CK0).

(36) But the Phoenix King had lent Tyrion the services of a unit of White Lions and these bold warriors' knowledge of their homeland was to prove invaluable (BNC:CM1).

(37) Military information is always particularly valuable (BNC:CDA).

(38) Such an invaluable and very rare nursing experience, nowadays. You are very fortunate! (BNC:CK0).

(39) But then Mr Hamilton found the valuable guns missing from Taigh na Tuir, and he reported that ... (BNC:CKF).

Certain domains are common to all five adjectives, although there are particular nouns that appear with one of the adjectives. These links are schematically reflected in Fig. 1.

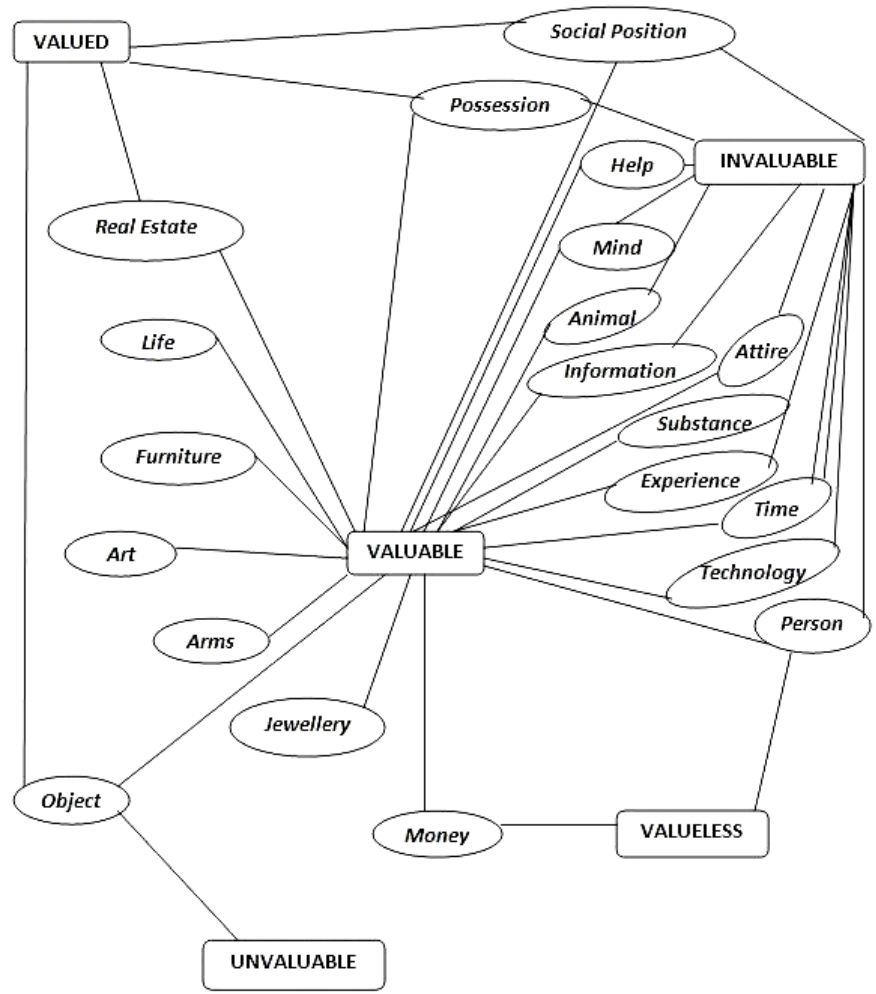

Fig. 1. 'Functional-Semantic Microfield of Adjectives Denoting Value'

The nouns of such semantic domains as Object (thing, artifact, stuff, item), Social Position (colleague, guest, agent, player, member, prisoner, friend, client, kinswoman, doctor, councilor, assistant), Possession (property, asset, acquisition, commodity), Person (man, person, she, he, I) are described by most of the evaluative adjectives. Thus, these categories form the nucleus of functional semantic microfield of value.

The categories linked with two adjectives form the so-called 'near' periphery: Real Estate (shop, palace, cottage, land, acres), Mind (knowledge, expertise, insight), Animal (breed, horse, cat, sheepdog, beast), Substance (psycurium, catalyst, phetam, drugs), Time (seconds, minutes, years, days), Technology (computer, photographs, disc, lever, kiln), Attire (dress, wig, mask, shoes), Help (assistance, co-operation, aid, contribution, service). While such categories as Jewellery (ring, diamond, beads), Furniture (oak dresser, furniture), Arms (gun, sword) or Art (master- 
piece, painting, watercolors, artworks, art-forms), described only by the adjective valuable, form 'distant' peripheral zone of the functional semantic microfield of value.

\section{3. Pragmatics}

From pragmatic perspective, the distinctive characteristic of the analyzed text fragments is a frequent use of hedges and boosters. According to Hyland, boosters (e. g. definitely..., I am sure that..., we firmly believe...) create an impression of certainty, conviction and assurance, and they can be used to instill trust and confidence in academic readers. Hedges (e. g. it would appear that..., there is a good reason to believe that..., may be possible...), on the other hand, are used to withhold the writer's commitment in order to protect him or her from too strong assertions, which may later prove to have been made in error [21]. Regarding hedges and boosters, linguistic literature on these elements often considers the two concepts as closely related, sometimes even inseparable from each other [22]. In our corpus we have revealed 151 text fragment containing boosters or hedges. This makes almost half of all the material. Such extensive usage of hedges can be explained by several factors. Firstly, evaluation always contains certain amount of subjectivity, and certain objects that are valuable for one person, may be of no value for another person. Thus, hedges and boosters function as tools to express the subjective evaluative attitude. Secondly, it should be emphasized that text samples belong to fictional discourse distinguished by author's worldview, system of values and attitudes.

According to our results, the number of boosters exceeds the number of hedges almost three times, showing the tendency to stress the value of important phenomena, rather than diminish it. The most frequently used devices for intensifying include adverbs: very, so, how, most, truly, more, really, such, particularly. Hedges are presented half by verbs (might, prove, would, may, will, think, could) and half by adverbs (perhaps, probably, quite, enough, likely, possibly) (Table 1).

Table 1

Hedging and Boosting in Fictional Discourse

\begin{tabular}{|c|c|}
\hline \multicolumn{2}{|r|}{ Hedges } \\
\hline 40 & Such detail might prove invaluable to French Intelligence at any debrief after my release (BNC:CEC). \\
\hline 41 & $\begin{array}{c}\text { It would have been invaluable to know what it was they really wanted from their association with } \\
\text { the Ping Tiao (BNC:G04) }\end{array}$ \\
\hline 42 & $\begin{array}{l}\text {... he wrote, wasting a whole life when something useful might have been salvaged, } \\
\text { something valuable perhaps ... (BNC:A08) }\end{array}$ \\
\hline 43 & Nevertheless, Theodora knew she had skills which could be valuable there (BNC:HA2). \\
\hline 44 & $\begin{array}{l}\text { You say your life is too precious to give it up for any country and yet it's not valuable enough for you to pay me two hun- } \\
\text { dred pounds not to shoot you (BNC:FRJ). }\end{array}$ \\
\hline 45 & The guns were sold. There were some that were quite valuable, a Churchill, I think, and a Boss ... (BNC:CKF) \\
\hline \multicolumn{2}{|r|}{ Boosters } \\
\hline 46 & 'So it must be valuable?' (BNC:HGD) \\
\hline 47 & $\begin{array}{r}\text { And, as we know only too well, every really valuable commodity falls, sooner or later, into the hands of some unscrupu- } \\
\text { lous individual ... (BNC:HWN) }\end{array}$ \\
\hline 48 & It is certainly valuable and I want it for myself (BNC:HGD). \\
\hline 49 & Good sheepdogs are always valuable ... (BNC:B0B) \\
\hline 50 & To the Ardakkeans, every tiny drop of phetam immeasurably, heart-breakingly valuable (BNC:G3G). \\
\hline 51 & $\begin{array}{c}\text { Loretta looked around curiously, taking in the shelves of books, the beautiful -- and obviously valuable -- antique } \\
\text { furniture ... (BNC:HTR) }\end{array}$ \\
\hline
\end{tabular}

Consequently, it can be presumed that such techniques as hedging and boosting provoke semantic vagueness of a text. They may cause shifts in semantic meaning, thus, reflecting pragmatic direction of the author, peculiarities of his/her view of value relations.

\section{Discussion}

Detailed study of evaluative adjectives valuable, valued, valueless, invaluable and unvaluable in fictional discourse provided the opportunity to establish certain language peculiarities of the whole category of value. The findings contribute to the study of English language world view 
and the hierarchy of values of English-speaking society. It would be effective to proceed with the research of other evaluative adjectives and adjectival phrases in different types of discourse (academic, newspaper, etc.).

\section{Conclusions}

Thus, in the process of our research on the basis of BNC we have created a corpus of sampled text fragments containing 5 evaluative adjectives with the common root valu(e). Two basic syntactic functions of the adjectives (attributive and predicative) have been defined. their variants.

We have determined three most common syntactic models (Adj+N; V+Adj; Adv.+Adj.) and

The analysis of functional and semantic relations of evaluative adjectives and the notions they denote has enabled us to model their functional semantic microfield. It has been ascertained that the use of different hedges and boosters impacts the meaning of evaluative adjectives, either weakening or strengthening it, or even shifting it to the opposite.

\section{References}

[1] Cabredo Hofherr, P., Matushansky, O. (2010). Adjectives formal analyses in syntax and semantics. Linguistics Today, vii, 335

[2] McNally, L., Kennedy, Ch. (2008). Adjectives and adverbs: Syntax, semantics, and discourse. Oxford Studies in Theoretical Linguistics, 19, 354.

[3] Baker, M. C. (2003) Lexical Categories: Verbs, Nouns and Adjectives. Cambridge: Cambridge University Press.

[4] Dixon, R. M. W., Aikhenvald, A. Y. (2004). Adjective Classes: A Cross-linguistic Typology. Oxford: Oxford University Press.

[5] Beck, D. (2002). The Typology of Parts of Speech Systems: The Markedness of Adjectives. London \& New York: Routledge.

[6] Truswell, R. (2009). Attributive Adjectives and Nominal Templates. Linguistic Inquiry, 40(3), 525-533. doi:10.1162/ling.2009.40.3.525

[7] Quirk, R., Greenbaum, S., Leech, G., Svartvik, J. (1992). A Grammar of Contemporary English. Singapore: Longman Singapore Publishers Pte Ltd.

[8] Crystal, D. (2003). The Cambridge Encyclopedia of the English Language. $2^{\text {nd }}$ Ed. Cambridge: Cambridge University Press.

[9] Eastwood, J. (2006). Oxford Learner's Grammar. Oxford: Oxford University Press.

[10] Close, R.A. (1975). A Reference Grammar for Students of English. London: Longman.

[11] Bolinger, D. L. (1961). Syntactic Blends and Other Matters. Language, 37(3), 366. doi: $10.2307 / 411078$

[12] Vendler, Z. (1968). Adjectives and Nominalizations. The Hague: Mouton and Co.

[13] Lasnik, H., Stowell, T. (1991). Weakest crossover. Linguistic Inquiry, 22, 687-720.

[14] Landau, I. (2006). Ways of Being Rude. Manuscript. Beersheba: Ben Gurion University.

[15] Barker, Ch. (2002). The dynamics of vagueness. Linguistics and Philosophy, 25, 1-36.

[16] Morley, G. D. (2004). Explorations in Functional Syntax: A New Framework for Lexicogrammatical Analysis. London: Equinox Publishing Ltd.

[17] O’Dwyer, B. (2006). Modern English Structures - Second Edition: Form, Function, and Position. Peterborough: Broadview Press.

[18] Strazny, P. (2005). Encyclopedia of Linguistics. NY: Routledge.

[19] Allen, K. (1995). Linguistic background: an outline of English syntax. In Natural Language Understanding (Chapter 2). Available at: https://mil.ufl.edu/6841/admin/JAllen_2-3.pdf

[20] The British National Corpus (BYU - BNC) Available at: https://corpus.byu.edu/bnc/

[21] Hyland, K. (1998). Exploring corporate rhetoric: metadiscourse in the CEO's setter. The Journal of Business Communication, 35 (2), 224-244. doi:10.1177/002194369803500203

[22] Grabe, W., Kaplan, R. B. (1997). On the Writing of Science and the Science of Writing: Hedging in Science Text and Elsewhere. Hedging and Discourse. doi:10.1515/9783110807332.151 